\title{
EFFECTS OF NOISE STRESS ON THYROID STIMULATING HORMONE IN ADULT RATS
}

\author{
Saba Saleem Safdar, Khadija Qamar, Khadija Mehboob, Tayyaba Faisal, Fahad Atta*, Aisha Ambreen** \\ Army Medical College/National University of Medical Sciences (NUMS) Rawalpindi Pakistan, *Quaid e Azam Medical College, Bhawalpur Pakistan, **Faisalabad \\ Medical University, Faisalabad Pakistan
}

\section{ABSTRACT}

Objective: To determine the effect of noise stress on thyroid stimulating hormone in adult rats.

Study Design: Laboratory-based experimental study.

Place and Duration of Study: Department of Anatomy, Army Medical College, Rawalpindi in collaboration with National Institute of Health, Islamabad, from Jan to Dec 2020.

Methodology: A total of 30 adult Sprague Dawley rats were distributed into three groups as ten rats/group. Group A served as the control group, rats in group B were exposed to $100 \mathrm{~dB}$ noise for continuous 4 hours / day for four months, and the rats in group $\mathrm{C}$ were exposed to $100 \mathrm{~dB}$ noise for continuous 6 hours/day for four months. At the end of the study, serum samples were collected from the rats' tail veins. Thyroid-stimulating hormone levels were compared among the groups.

Results: At the start of the study, mean serum thyroid stimulating hormone level of control group A rats was $0.34 \pm 0.15$ $\mu \mathrm{IU} / \mathrm{ml}$. Mean serum thyroid stimulating hormone level of experimental groups B and C rats at the start of the study was 0.46 $\pm 0.18 \mu \mathrm{IU} / \mathrm{ml}$ and $0.41 \pm 0.14 \mu \mathrm{IU} / \mathrm{ml}$, respectively Mean serum thyroid stimulating hormone of rats did not differ statistically significantly between the group $p=0.26$, By the end of study mean serum thyroid stimulating hormone level of control group A rats was $0.6 \pm 0.2 \mu \mathrm{IU} / \mathrm{ml}$. Mean serum thyroid stimulating hormone levels of experimental groups $B$ and $C$ rats at the end of the study were $1.32 \pm 0.35 \mu \mathrm{IU} / \mathrm{ml}$ and $1.86 \pm 0.67 \mu \mathrm{IU} / \mathrm{ml}$, respectively, Mean serum thyroid stimulating hormone of rats differed significantly between the groups $p<0.001$.

Conclusion: Loud noise exposure can lead to an increased level of mean serum thyroid stimulating hormone levels in adult rats.

Keywords: Noise pollution, Rat, Thyroid gland, Thyroid stimulating hormone.

This is an Open Access article distributed under the terms of the Creative Commons Attribution License (https://creativecommons.org/licenses/by-nc/4.0/), which permits unrestricted use, distribution, and reproduction in any medium, provided the original work is properly cited.

\section{INTRODUCTION}

Noise is a chronic environmental stressor defined as an unwanted, unpleasant, or unpredictable sound, or a combination of sounds 1 . The adverse health problems imposed by exposure to noise stress include hearing loss, sleep disturbances, poor concentration, cognitive impairment, endocrinal disturbances, cardiovascular and metabolic implications ${ }^{2-4}$.

Moreover, human body exposure to noise pollution affects vital functions such as body temperature, heart rate, nervous system, breathing, body weight, muscle strength ${ }^{5}$. Thyroid hormones potentially regulate all these functions, and deregulation of thyroid functions can adversely affect these vital signs. In addition, the features of depression, fatigue, memory loss, and weight gain associated with noise exposure can be explained by poor thyroid gland functionality induced by noise stress ${ }^{6}$. Hence, the impact of environmental noise exposure on the human thyroid gland's functional integrity is vital to be considered.

Keeping in mind, this study is designed to analyze the effect of different durations of noise exposure

Correspondence: Dr Saba Saleem Safdar, Department of Anatomy, Army Medical College Rawalpindi Pakistan

Received: 11 Jun 2021; revised received: 01 Jun 2021; accepted: 05 Jul 2021 on thyroid stimulating hormone of adult rats. The effect of noise exposure on human health may vary depending upon the intensity and duration of noise exposure. The thyroid gland majorly influences the vital functioning of many organ systems of the body and is regulated closely by the hypothalamic-pituitary axis7 .

Thyroid stimulating hormone (TSH) is a glycoprotein, released from the anterior pituitary, also known as thyrotropin. TSH consists of 211 amino acids, with a and $\beta$ subunits ${ }^{8}$. Functional activity of TSH resides in its $\beta$ subunit which increases thyroid hormones production via cAMP-mediated second messenger system by enhancing the release of stored thyroid hormones via stimulating proteolysis of thyroglobulin, Iodide trapping by enhancing sodium-iodide cotransporter, increasing organification of tyrosine residues of thyroglobulin and hypertrophy and enhanced secretory activity of the follicular cells9.

TRH is secreted from neurons in the hypothalamus's paraventricular nucleus, which stimulates anterior pituitary TSH production and release ${ }^{7}$. However, the most potent and practically important regulator of TRH and hence TSH production is negative feedback regulation by circulating thyroid hormone levels and more specifically by $\mathrm{T} 3^{7}$. 
Keeping in mind the key role of TSH in regulating the function of the thyroid gland, this study was aimed at determining the effect of noise stress on serum thyroid stimulating hormone levels in adult rats.

\section{METHODOLOGY}

This laboratory-based experimental study was carried out as per the rules and regulations regarding the handling and care of animals set forth by the ethics committee of the Army Medical College/National University of Medical Sciences (NUMS), from January to December 2020, at the department of Anatomy, Army Medical College, Rawalpindi/National University of Medical Sciences (NUMS) in collaboration with the National Institute of Health (NIH), Islamabad.

The study sample included 30 (15 male and 15 female Sprague Dawley rats) selected by non-probability consecutive sampling. Healthy male and female rats of an average weight of $250 \pm 50$ grams were procured from the National Institute of Health, Islamabad, and included in the study. While female pregnant rats or rats with any gross injury/abnormality were excluded. Rats were kept in partially ventilated separate cages in NIH's animal house.Rats were kept under standard laboratory conditions of temperature $21 \pm 2^{\circ}$ $\mathrm{C}$ and a 12-hour light/dark cycle. The rats were fed on standard laboratory rat chow and water ad libitum. Rats were divided into three groups, including ten rats (five male and five female) per group: group A (control group): rats in group A served as controls. They were given a standard diet and water ad libitum for four months. Group B (experimental group): This group contained ten rats exposed to $100 \mathrm{~dB}$ noise for continuous 4 hours per day from 9:00 am to 1:00 pm for four months with standard food and water ad libitum. Group C (experimental group): this group contained ten rats exposed to $100 \mathrm{~dB}$ noise for continuous 6 hours per day from 9:00 am to 3:00 pm for 4 months with standard food and water ad libitum.

Twenty sprague dawley males and females assigned to experimental groups $B$ and $C$ were exposed to recorded pure tone noise stress, purchased from the local market. An uninterrupted power supply was provided with a DC adopter and stand by battery of nine volts. A sound level decibel meter was placed outside the cages to measure and maintain noise intensity (radio shack analogue model 33-4050). The intensity of sound was recorded at the start and end of the experiment.

At the start and end of the experiment, blood samples were drawn from the rats' tail vein for mea- suring the serum TSH levels ${ }^{10}$. For this purpose, rats were contained individually in a plastic tube restrainer, and the tails were washed with a dilute disinfectant solution. Then, using the thumb and index finger, the right lateral tail vein was raised.

Two-millilitre blood was collected from the localized vein, $1 / 3^{\text {rd }}$ of the tail's length from the tail tip, via a $21 \mathrm{G}$ sterile needle. Collected blood was shifted into labelled and sterile plastic vials. Vials were then placed vertically in the stand, allowed to clot, and retract at room tempe-rature. After half an hour, the blood samples were cen-trifuged at 5000 revolutions per minute, for 15 minutes by centrifuge machine (EBA 20 Hettich). Separated sera were collected into labelled polypropylene storage tubes and stored at $-20^{\circ} \mathrm{C}$ for later determination of serum TSH levels. Serum TSH levels were measured by using Enzyme Immunoassay (EIA) test kit for TSH.

The data was entered using a statistical package for social sciences (SPSS-26). Mean serum Thyroidstimulating hormone levels at the start and end of the study were compared among the groups via one-way ANOVA after looking for the assumptions. One-way ANOVA was followed by post-hoc Tuckey test for pairwise comparison among groups. The $p$-value of $\leq 0.05$ was considered significant.

\section{RESULTS}

A total of 30 sprague dawley rats $15(50 \%)$ male and $15(50 \%)$ female were included, mean weight was $250 \pm 50$ grams. At the start of the study, mean serum TSH level of control group A rats was $0.34 \pm 0.15 \mu \mathrm{IU} /$ $\mathrm{ml}$. Mean serum TSH level of experimental groups B and $C$ rats at the start of the study was $0.46 \pm 0.18 \mu \mathrm{IU} /$ $\mathrm{ml}$ and $0.41 \pm 0.14 \mu \mathrm{IU} / \mathrm{ml}$, respectively.

Mean serum TSH of rats did not differ statistically significantly bet-ween the group $p=0.26$, by the end of study mean se-rum TSH level of control group A rats was $0.6 \pm 0.2 \mu \mathrm{IU} / \mathrm{ml}$. Mean serum TSH levels of experimental groups $\mathrm{B}$ and $\mathrm{C}$ rats at the end of the study were $1.32 \pm 0.35 \mu \mathrm{IU} / \mathrm{ml}$ and $1.86 \pm 0.67 \mu \mathrm{IU} / \mathrm{ml}$, respectively, table-I. Mean serum TSH of rats differed significantly bet-ween the groups $p<0.001$, (table-I).

Mean serum TSH of rats differed significantly between the groups, at the end of study. The group $\mathrm{C}$ rats had higher serum TSH levels as compared to the control group A and experiment group B, a statistically significant $p=0.03$ and $p<0.001$ respectively, simliary group Brats had higher serum TSH levels as compared to the control Group A $p<0.001$ shown in table-II. 
Table-I: Comparison of serum thyroid stimulating hormone levels of rats between start and end of the study within groups.

\begin{tabular}{l|c|c|c|c}
\hline Parameters & $\begin{array}{c}\text { Group- } \\
\mathbf{1}\end{array}$ & $\begin{array}{c}\text { Group- } \\
\mathbf{2}\end{array}$ & $\begin{array}{c}\text { Group- } \\
\mathbf{3}\end{array}$ & $\begin{array}{c}\boldsymbol{p} \text { - } \\
\text { value }\end{array}$ \\
\hline Initial Serum TSH & $0.34 \pm$ & $0.46 \pm$ & $0.41 \pm$ & 0.26 \\
Level $(\mu \mathrm{IU} / \mathrm{ml})$ & 0.15 & 0.18 & 0.14 & 0.26 \\
\hline Final Serum TSH & $0.60 \pm$ & $1.32 \pm$ & $1.86 \pm$ & $<0.001$ \\
Level $(\mu \mathrm{IU} / \mathrm{ml})$ & 0.20 & 0.35 & 0.67 & \\
\hline
\end{tabular}

Table-II: Inter-group comparison of serum thyroid stimulating hormone levels of rats between start and end of the study within groups.

\begin{tabular}{l|c|c|c}
\hline $\begin{array}{l}\text { Group } \\
\text { Comparison }\end{array}$ & $\begin{array}{c}\text { Group-1 } \\
\text { Vs. } \\
\text { Group-2 }\end{array}$ & $\begin{array}{c}\text { Group-2 } \\
\text { Vs. } \\
\text { Group-3 }\end{array}$ & $\begin{array}{c}\text { Group-1 } \\
\text { Vs. } \\
\text { Group-3 }\end{array}$ \\
\hline $\begin{array}{l}\text { Final Serum TSH } \\
\text { Level }(\mu \mathrm{IU} / \mathrm{ml})\end{array}$ & $<0.001$ & $<0.001$ & 0.03 \\
\hline
\end{tabular}

\section{DISCUSSION}

In the context of increasing globalization and technological enhancements, human beings are exceedingly exposed to noise stress worldwide. Considering the epidemiological statistics of noise exposure, and its adverse health hazards, there is a dire need to generate potential evidence for the effect of environmental noise stress on the thyroid gland's structural and functional integrity. For this purpose, the study was designed to analyze the impact of variable duration of noise stress exposure on thyroid stimulating hormone of adult rats.

The noise is defined as an unwanted/unpleasant or unpredictable sound or combination of sounds ${ }^{1}$. It is now increasingly believed that noise pollution is a chronic environmental stressor that has long-lasting adverse effects on health, society, environment and economics ${ }^{1}$. As per NIOSH guidelines, recommended maximum noise exposure is 85 decibels, for an average of 8 -hours/day ${ }^{11}$. In addition to the direct impact on hearing, chronic exposure to noise stress is a cause of psychological and physiological impairments as cardiovascular morbidities, including ischemic heart diseases $^{12}$. Other cardiovascular diseases associated with chronic noise stress include arterial hypertension, stroke, arrhythmia and heart failure ${ }^{12-15}$. Noise exposure can also lead to depression, anxiety, metabolic and sleep disturbances.

This study's objective was to determine the effects of noise stress on the thyroid profile of adult rats' thyroid glands. For this purpose, 30 (15 males and 15 female) adult Sprague Dawley rats were distributed into three groups as ten rats/group. Group A served as the control group, rats in group B were exposed to $100 \mathrm{~dB}$ noise for continuous 4 hours per day for four months, and the rats in group $\mathrm{C}$ were exposed to $100 \mathrm{~dB}$ noise for continuous 6 hours per day for four months. At the end of the study, the mean serum TSH levels of experimental groups $B$ and $C$ were significantly higher as compared to the control group rats.

A previous study also reported that acute exposure to noise stress raised serum T3 and decreased serum TSH among rodents, whereas serum T3 was reduced along with raised TSH among rodents exposed to chronic noise exposure ${ }^{16}$. Prolonged exposure to stress among rodents in another study also resulted in decreased serum T3 and TSH, increased rT3, and no change in serum $\mathrm{T} 4{ }^{17}$. In the current study, raised serum TSH levels are observed among experimental groups, whereas the significantly higher rise of serum TSH is exhibited by rats exposed to longer duration of noise stress. However, this study has the limitation of only reporting the serological findings of TSH and has not counted for observing the functional markers of thyroid gland activity i.e., serum T3 and T4 levels.

Some evidence of altered thyroid gland functioning is also available among human cohorts exposed to variable stress sources. Among a human cohort exposed to the acute stress of heavy intraperitoneal surgery, decreased free and total T3, increased rT3, free T4 and TSH were reported ${ }^{17}$. Whereas, people with chronic posttraumatic stress exhibited impaired peripheral conversion of T4 to T3, increased production of rT3 and decreased thyroid axis ${ }^{17}$. Thyroid profile of another group of people exposed to long-term environmen-tal stress (high altitude and cold exposure) exhibited decreased serum T3 and increased rT3 and cortisol ${ }^{17}$.

A comparative study among healthy cohorts of occupational exposure to long-term noise stress was made with a healthy cohort of no such occupational, environmental exposure of noise. Among the people exposed to occupational noise stress, $11.65 \%$ exhibited thyroid functional dysregulation compared to only $2.85 \%$ in the comparative group ${ }^{18}$. Impact of stressinduced thyroid dysfunction has also been supported by experimentation among other species. Hypothyroidism, evident by reduced free T3 levels and increased TSH levels, has been exhibited among storks, cockerels, newt Triturus carnifex, turtles, and fish Oreochromis niloticus after chronic stress exposure ${ }^{17}$. Results of this study are suggestive of hyperfunctioning of the thyroid gland in response to noise stress exposure which may be prodromal to the findings of hypothyroidism in the above-mentioned studies, as chronic exposure to loud noise stress may ultimately result in exhaustion and hypo-functioning of thyroid follicles. 
A widely accepted explanation of noise stressinduced thyroid gland impact is dysregulation of the hypothalamic-pituitary-thyroid axis, probably because of altered TSH production ${ }^{19}$. This altered TSH production and sensitivity are further attributed to glucocorticoid-induced variation in the hypothalamic-pituitaryadrenal axis, upon exposure to chronic stress ${ }^{17}$. Among rats exposed to chronic stress, thyroid dysregulation is also proposed on behalf of impaired T3 negative feedback to TSH, caused by glucocorticoids ${ }^{17}$. In addition, epigenetics might also come into play to dysregulate thyroid gland functioning, e.g, glucocorticoid-induced parallel feedback suppression of CRH mRNA and proTRH mRNA in the paraventricular hypothalamic nucleus. Besides, chronic stress may alter thyroid hormones regulation, production, secretion, and metabolism by altering the deiodinase activity in the target tissue, decreasing thyroid binging globulin via transcriptional modification, altering the Iodide uptake pump activity or affecting the activity of thyroid peroxidases and lysosomal hydrolases ${ }^{17}$.

This study was designed to compare the effect of different durations of noise exposure on the thyroid profile in adult rats in relation to combine with hypothalamic-pituitary-thyroid axis review. The results highlighted the hyperactivity of thyroid follicles in relation to raised serum TSH levels, upon exposure to loud noise stress. However, the results were not considerably different among experimental groups exposed to the variable duration of loud noise. Future research with a broader perspective should be conducted for conclusive remarks and better generalization of these findings. Future studies conducted to explore the effect of noise stress on thyroid glands should also include the functional profile like thyroid hormones (T3 and T4) and histopathological analysis.

Further, such experimental studies should be designed among rodent models with variable duration and intensity of noise exposure to help comment on the safety profile with respect to the thyroid gland.

As this study results are supported by the data from relevant research in experimental models of other species, standardized observational and experimental studies should also be conducted among human cohorts exposed to loud noise stress for conclusive remarks.

\section{CONCLUSION}

Loud noise exposure can lead to raised serum thyroid stimulating hormone levels in adult rats.

\section{CONFLICT OF INTEREST}

This study has no conflict of interest to be declared by any author.

\section{REFERNCES}

1. Tompkins OS. Secondhand noise and stress. Aaohn J 2009; 57(10): 436-40.

2. Nieuwenhuijsen MJ, Ristovska G, Dadvand P. WHO environm-ental noise guidelines for the European region: a systematic re-view on environmental noise and adverse birth outcomes. Int J Environ Res Public Health 2017; 14(10): 1252-58.

3. WHO. Environmental noise guidelines for the European region 2018. [Internet] Available at: https:/ / apps.who.int/iris/bitstream/handle/ 10665/279952/9789289053563-eng.pdf [Accessed: 28 Dec 2020].

4. Luca M, Guzik T, Luca A. Oxidative stress as a link between cerebrocardiovascular and psychiatric disorders. Oxid Med Cell Longev 2020; 2020(2): 5685317-20.

5. Mariotti A. The effects of chronic stress on health: new insights into the molecular mechanisms of brain-body communication. Future Sci OA 2015; 1(3): FSO23-28.

6. Gaitonde DY, Rowley KD, Sweeney LB. Hypothyroidism: an update. S Afr Fam Pract 2012; 54(5): 384-90.

7. Hall JE, Hall ME. Guyton and Hall textbook of medical phy-siology e-Book. 14 ${ }^{\text {th }}$ ed. Philadelphia: Elsevier Health Sciences; 2020 [Internet] Available at: https:/ /www.us. elsevierhealth.com /guyton-and-halltextbook-of-medical-phy-siology-9780323597128.html

8. Barrett KE, Boitano S, Barman SM, Brooks HL. Ganong's review of medical physiology 26 ed. New York: MC Graw Hill; 2019. p. 337-50.

9. Boron WF, Boulpaep EL. Medical physiology E-book. $3^{\text {rd }}$ ed: Elsevier Health Sciences; 2016. [Internet] Available from: https://accessmedicine.mhmedical.com/book.aspx?bookID $=2525$.

10. Harikrishnan V, Hansen AK, Abelson KS, Sørensen DB. A comparison of various methods of blood sampling in mice and rats: effects on animal welfare. Lab Anim 2018; 52(3): 253-64.

11. Murphy WJ, Eichwald J, Meinke DK, Chadha S, Iskander J. CDC grand rounds: Promoting hearing health across the lifespan. Morb Mortal Wkly Rep 2018; 67(8): 243-46.

12. Hahad O, Prochaska JH. Environmental noise-induced effects on stress hormones, oxidative stress, and vascular dysfunction: key factors in the relationship between cerebrocardiovascular and psychological disorders. Oxid Med Cell Longev 2019; 2019(2): 4623109.

13. Bolm-Audorff U, Hegewald J, Pretzsch A, Freiberg A, Nienhaus A. Occupational noise and hypertension risk: a syste-matic review and meta-analysis. Int J Environ Res Public Health 2020; 17(17): 6281-85.

14. Nilsson M. Biological mechanisms related to cardiovascular and metabolic effects by environmental noise 2018. [Internet] Avail-able at: https://www.euro.who.int/en/health-topics/ environ-ment-andhealth/noise/publications/2018/biological-mechanisms-related-tocardiovascular-and-metabolic-effects-by-environmental-noise, 2018. [Accessed on December 30, 2020].

15. Singh D, Kumari N. A review of adverse effects of road traffic noise on human health. Fluct Noise Lett 2018; 17(01): 1830001.

16. Ababzadeh S, Razavinia FS, Farsani ME, Sharifimoghadam S, Moslehi A, Faghani D. Effect of short-term and long-term traffic noise exposure on the thyroid gland in adult rats: a sexual dimorphic study. Horm Mol Biol Clin Investig 2020; 42(1): 29-35.

17. Nadolnik L. Stress and the thyroid gland. Biochem (Mosc) Suppl Ser B: Biomed Chem 2011; 5(2): 103-12.

18. Veljović V, Jovanović J, Radević L. Early detection of thyroid disease in workers pro-fessionally exposed to noise through preventive medical check-ups. Acta Med Median 2010; 49(3): 45-48.

19. Kurien MJ, Rajagopalan A, Sailesh KS, Varghese V, Amin A, Reddy UK. Stress, thyroid hormone secretion and vestibular stimulation: a review of the links. BEMS Rep 2015; 1(2): 31-34. 